\title{
CONHECIMENTOS E PRÁTICAS DE TRABALHADORES DE UMA CRECHE ACERCA DO ALEITAMENTO MATERNO
}

\section{KNOWLEDGE AND PRATICES IN BREASTFEEDING PROMOTION BY WORKERS OF A CHILD DAY CARE CENTER}

Aline Ferreira Maciel ${ }^{1}$

Maria De La Ó Ramallo Veríssimo ${ }^{2}$

Maciel AF; Veríssimo MLÓR. Conhecimentos e práticas de trabalhadores de uma creche acerca do aleitamento materno. Rev. Bras. Cresc. e Desenv. Hum. 2010, 20(3) 688-698.

Resumo: Sendo o aleitamento materno um comportamento que pode ser influenciado por fatores ambientais e pessoais, este estudo objetivou caracterizar conhecimentos e práticas de trabalhadores de uma creche acerca dessa ação. Foram entrevistados dez trabalhadores de um Centro Infantil (CI) que atuaram com crianças menores de um ano, no período de 2003 a 2007. Os resultados originaram quatro temas. O primeiro, A Importância do Aleitamento Materno na Creche, destaca sua relação com o desenvolvimento infantil, com a adaptação ao CI e com o vínculo materno, evidenciando que os conhecimentos são provenientes da prática diária ou da mídia. Tais conhecimentos empíricos são repassados às mães no momento da matrícula e em outros contatos e podem impactar na manutenção ou não do aleitamento. $\mathrm{O}$ tema $O$ aleitamento depende do interesse das mães aponta que elas frequentemente desistem de aleitar e que tal decisão resulta da falta de persistência em superar dificuldades relativas ao trabalho, pois seu acesso ao CI para amamentar é livre. Quanto às facilidades relacionadas ao aleitamento materno na creche, surge o apoio oferecido pela instituição, a garantia legal ao aleitamento e suas práticas de reforçar a importância do aleitamento para as mães. As dificuldades relacionadas ao aleitamento na creche incluem a distância entre o local de trabalho e o CI e a relação de dependência quando da manutenção do aleitamento, para os funcionários. A formação de uma rede de apoio à amamentação, com instituições de saúde, possibilitaria preparar os trabalhadores do Centro Infantil quanto aos benefícios do aleitamento materno e às estratégias de ação para que fossem agentes promotores dessa prática.

Palavras-chave: aleitamento materno; creches; educação infantil.

Enfermeira. Mestra em Enfermagem Pediátrica na Escola de Enfermagem da Universidade de São Paulo.

2 Enfermeira. Professora Doutora na Escola de Enfermagem da Universidade de São Paulo - EEUSP. Departamento de Enfermagem Materno- Infantil e Psiquiátrica.

Correspondência para: São João das Duas Barras, 95 - Itaquera. CEP: 08270-080. São Paulo/SP. E-mail: aline.maciel@fasm.edu.br Tel. (11) 2217-9110.

Baseado na Dissertação de Mestrado: Maciel. AF.Conhecimentos e práticas de trabalhadores de um centro infantil acerca do aleitamento materno. São Paulo, 2008. Escola de Enfermagem da USP. Orientadora: Maria de La Ó Ramallo Veríssimo. 


\begin{abstract}
Since breastfeeding is a behaviour which can be influenced by environmental and personal factors, this study aimed to characterize the workers' knowledge and practices of a Child Day Care Center regarding to this action. Ten professionals of a Child Center (CC) who worked from 2003 to 2007 caring for infants under one year old were interviewed. The results were organized in four themes. The first one, The Importance of Breastfeeding at the Day Care Center, highlights its relation to the infant's development, to the adaptation of the children to CC and to child's connection to mother. Probably those are empirical knowledge, which come from the daily practice or the media. When they are reinforced to the mothers at the child's enrollment and during other contacts they can impact on keeping or not breastfeeding. The theme Breastfeeding depends on the mother's interest points out that mothers often give up breastfeeding and that decision comes from lack of persistence in overcoming difficulties related to work, once their access to $\mathrm{CC}$ for breastfeeding is free. Regarding to Easiness Related to Breastfeeding at the Day Care Center, it is emphasized the support offered by the facility, the legal guarantee to breastfeeding and the practices of the workers to reinforce the importance of breastfeeding to the mothers. The Difficulties Related to Breastfeeding at the Day Care Center comprise the distance between workplace and the $\mathrm{CC}$, as well the dependence of the workers to waiting the mother for breastfeeding. The development of a breastfeeding support network with healthcare facilities would strengthen the $\mathrm{CC}$ workers regarding to the benefits of breastfeeding and to the action strategies to promote this practice.
\end{abstract}

Key words: Breastfeeding; day care centers; child instruction.

\section{INTRODUÇÃO}

O aleitamento materno é o modo mais adequado de fornecer alimento para o crescimento e o desenvolvimento saudável de lactentes, com influência também na saúde biológica e emocional do binômio mãe-filho, uma vez que é um alimento completo, devendo ser a única fonte de hidratação e alimentação nos primeiros seis meses de vida ${ }^{1-3}$. Tanto que organizações nacionais e internacionais preocupam-se em estabelecer e difundir estratégias que incentivem e propiciem essa prática ${ }^{4}$.

As vantagens da amamentação, especialmente nos primeiros meses de vida, são inúmeras e estão sendo cada vez mais difundidas pelos profissionais de saúde e até mesmo veiculadas na mídia. Todavia, mesmo com todas essas vantagens, o aleitamento materno não vem sendo praticado como deveria, havendo altas taxas de desmame em crianças menores de seis meses. Entende-se que isso se dá por conta da complexidade que envolve o ato de amamentar, que é um comportamento humano e, como tal, é permeado por significados e influências socioculturais ${ }^{5,6}$.

As práticas atuais relacionadas à promoção do aleitamento materno estão pautadas no discurso psicobiológico que enfatiza as vantagens nutricionais, imunológicas, psicológicas, entre outras, relacionadas à amamentação, que beneficiam a criança e sua família; no entanto, poucos autores abordam essa prática como um processo amplo e permeado por fatores complexos que possuem difícil explicação ${ }^{7,8}$.

Às vezes, prevalece uma visão romântica do aleitamento materno, sendo enfatizado como um ato de amor; entretanto, deve-se lembrar que mesmo não amamentando ao seio, a mulher é capaz de desenvolver o amor materno 5 .

Muitas pessoas creem que as dificuldades maternas resumem-se às fissuras e ao 
ingurgitamento mamário, ficando de lado os aspectos socioculturais que realmente influenciam a decisão de amamentar.

Assim, todos os envolvidos com o aleitamento materno, sejam eles enfermeiros, médicos, educadores infantis, avós, pais, entre outros, precisam compreender que ele vai muito além de um ato "instintivo materno" de oferecer alimento ao filho, uma vez que é perpassado por conhecimentos, crenças e atitudes que influenciam esse importante comportamento e que, mesmo o aleitamento sendo um ato biologicamente determinado, a expectativa biológica contrapõe-se às expectativas culturais e não se podem enfatizar apenas seus pontos positivos no discurso da saúde.

Sob essa óptica, traz-se a creche como um local onde o aleitamento materno deve ser promovido e os profissionais que cuidam dessas crianças devem estar preparados para apoiar e incentivar essa prática.

As primeiras creches brasileiras foram concebidas na vertente do amparo e da assistência às crianças desprotegidas, todavia, atualmente, o acesso a essas instituições vem sendo difundido não apenas como direito da mãe trabalhadora, mas também da criança como cidadã, mudando o foco assistencialista para o educacional ${ }^{9}$.

De acordo com a LDB, as creches e préescolas têm como finalidade o atendimento em educação infantil, contemplando as necessidades de desenvolvimento intelectual e o acesso ao saber, bem como o direito à socialização, às vivências infantis e aos cuidados assistenciais específicos e necessários ${ }^{10}$.

Os profissionais que atuam com as crianças nas creches são designados educadores infantis, uma vez que contribuem para sua formação e crescimento por meio do cuidado e da educação prestados a elas.

O educador não é apenas aquele que toma conta, mas sim alguém que cuida e contribui ativamente para o desenvolvimento da criança. $\mathrm{O}$ ato de cuidar demanda uma liga- ção afetiva entre educador e criança. Para dar conta das necessidades básicas da criança, o adulto precisa estar atento a ela. Essa relação envolve afetividade e sensibilidade para perceber o que ela precisa, pois, para atender às necessidades, é preciso antes saber como reconhecê-las e de que forma atendê-las ${ }^{11}$.

No caso do aleitamento materno, não só estão em jogo as necessidades da criança, como também as da mãe. É preciso considerar esse processo sob a perspectiva da mulher, compreendendo o que ela pensa sobre si e reconhecer as influências culturais que a cercam, visando ajudá-la a tomar decisões para aleitar ou não. Tal função pode ser encarada como um desafio capaz de evitar o desmame precoce e minimizar seus fatores de risco, uma vez que as creches são equipamentos sociais em benefício da criança.

Os trabalhadores de creches devem ser promotores de saúde, orientando e incentivando as mães na manutenção do aleitamento materno, pois muitas crianças começam a frequentar essas instituições durante o primeiro ano de vida, período em que o leite materno é sua principal fonte de alimento. Contudo, não basta que eles tenham intenção de fazer isso, é preciso que se preparem, aprendendo sobre como realizar esse apoio. Além disto, é preciso conhecer o sentido que esses trabalhadores conferem à amamentação, pois, como já mencionado, esse é um ato humano, permeado por crenças e valores e, de acordo com essas autorreferências, o trabalhador decide se vai ou não incentivar o aleitamento materno na creche.

Desta maneira, os objetivos são de caracterizar conhecimentos e práticas de trabalhadores de uma creche relativos ao aleitamento materno e identificar a percepção de trabalhadores de uma creche sobre a oferta de leite materno para a criança sob seus cuidados, bem como conhecer as facilidades e dificuldades relacionadas ao aleitamento materno no serviço, segundo seus trabalhadores; 
e identificar ações relacionadas ao aleitamento materno realizadas por eles no atendimento às crianças e mães.

\section{MÉTODO}

Trata-se de estudo qualitativo, realizado em um Centro Infantil (CI) vinculado a um hospital de ensino de grande porte localizado na Zona Leste da capital paulistana, agregado à Coordenadoria de Educação de Itaquera. Salienta-se que foi utilizado o termo Centro Infantil como sinônimo de creche, por ser assim empregado na rede municipal de São Paulo.

A opção por esse CI deu-se porque a pesquisadora formou-se e atua na instituição de ensino ligada ao hospital referido, além de morar e trabalhar como enfermeira no bairro, escolhendo-o com o intuito de conhecer melhor suas necessidades, na intenção de poder utilizar esses subsídios em sua prática profissional, contribuindo para a melhoria do cuidado à criança.

Atualmente, a instituição recebe 360 crianças de até três anos, 11 meses e 29 dias e conta com 41 funcionários. A equipe é composta por uma diretora, vinte e dois auxiliares de desenvolvimento infantil (ADI's), uma auxiliar de enfermagem, um cozinheiro, cinco auxiliares de cozinha, oito ajudantes gerais, uma costureira, uma recepcionista e um auxiliar administrativo.

Os filhos de funcionárias só permanecem na instituição em período parcial, ou seja, no período da jornada de trabalho de suas mães. Já as crianças matriculadas por via de um convênio com a Prefeitura ficam em horário integral, das $7 \mathrm{~h}$ às $17 \mathrm{~h}$. Ressalta-se que o ingresso dos filhos de funcionárias se dá a partir dos quatro meses de idade, enquanto as crianças matriculadas pelo convênio só podem ser admitidas após completarem um ano.

Assim, tem-se que a experiência dos profissionais do CI com aleitamento materno ex- clusivo acontece somente com os filhos de funcionárias do hospital.

Os critérios de inclusão para participação no estudo foram trabalhadores do CI que tivessem atuado com crianças menores de um ano, durante o período de 2003 a 2007, portanto, potencialmente vivido experiências de aleitamento materno na creche. Com esses critérios, dez sujeitos participaram, incluindo auxiliares de desenvolvimento infantil, a auxiliar de enfermagem, o auxiliar administrativo e a diretora. Obteve-se a participação espontânea de todos os trabalhadores.

O projeto foi aprovado pelo Comitê de Ética da Escola de Enfermagem da Universidade de São Paulo (processo $n^{\circ} 708 / 2008 /$ CEP - EEUSP) e submetido à direção do Centro Infantil. Além disso, os trabalhadores assinaram um termo de consentimento livre e esclarecido.

As percepções dos trabalhadores foram coletadas por meio de entrevistas semiestruturadas, conduzidas por meio das seguintes questões: Vivenciando a prática de cuidar de crianças menores de um ano, como você percebe o aleitamento materno na creche? Em sua opinião, a creche é um bom lugar para as mães amamentarem? Por quê? Em sua opinião, existem dificuldades para o aleitamento materno na creche? Quais? Em sua opinião, existem facilidades para o aleitamento materno na creche? Quais? O que a creche faz quando entra um bebê que ainda é amamentado? E você como procede?

Todas as entrevistas foram gravadas e transcritas pela autora, de acordo com as normas para transcrição ${ }^{12}$, que estabelece o uso dos seguintes sinais, possibilitando que a leitura ofereça uma visão mais próxima do discurso original:

( ) para incompreensão de palavras ou segmentos;

(hipótese) para hipótese do que se ouviu;

/ truncamento (havendo homografia, usa-se acento indicativo da tônica e/ou timbre); 
uso de maiúscula quando houver entonação enfática;

:: alongamento de vogal ou consoante, podendo aumentar para mais :::

- silabação

? interrogação

... qualquer pausa

(( minúscula)) comentários descritos pelo transcritor

- comentários que quebram a sequência temática da exposição; desvio temático;

[ superposição, simultaneidade de vozes;

(...) indicação de que a fala foi tomada ou interrompida em determinado ponto. Não no seu início.

“ ” citações literais, reproduções de discurso direto ou leituras de textos, durante gravação.

\{\} inserção feita pela autora desta pesquisa, a fim de facilitar a compreensão do discurso.

Em seguida, as entrevistas foram submetidas à estratégia de Análise de Conteúdo.

\section{RESULTADOS}

Participaram do estudo sete auxiliares de desenvolvimento infantil, uma auxiliar de enfermagem, um auxiliar administrativo e a diretora da instituição. Suas idades variaram entre 25 a 58 anos, sendo a média de 41,5 anos. Nove participantes são do sexo feminino e um do sexo masculino. Dentre três que não chegaram ao ensino médio, um tinha ensino fundamental incompleto e dois concluíram o ensino fundamental. Um respondente tem ensino médio incompleto e dentre os cinco que têm ensino médio completo, dois fizeram magistério e um fez curso técnico em enfermagem; apenas um dos participantes tem curso superior em pedagogia.

O tempo de atuação desses profissionais na educação infantil e o tempo de atuação deles dentro da instituição variou de quatro a 29 anos, sendo a média de 16,5 anos. Todos refe- riram que trabalhavam com crianças por opção e cumpriam jornada de 44 horas semanais.

Os resultados deste estudo foram agrupados em quatro grandes temas. São eles: A Importância do Aleitamento Materno na Creche, A Prática do Aleitamento Materno Depende das Mães, Facilidades Relacionadas ao Aleitamento Materno na Creche e Dificuldades Relacionadas ao Aleitamento Materno na Creche.

A primeira questão formulada aos respondentes do estudo (identificados nas falas como $\mathrm{R}$, seguido dos numerais 1 a 10) referiu-se a sua percepção acerca do aleitamento materno na creche. Ao respondê-la, grande parte do grupo iniciou sua fala reconhecendo a importância do aleitamento materno:

"eu acho que o aleitamento materno é:: muito importante (...) e a gente sabe que é importante pra ela... na fase bebê.:... até pelo menos seis meses ser BEM frequente... nos horários tudo" $R 3$

A razão mais lembrada para justificar tal importância é sua relação com a saúde, pois ele previne doenças, além de auxiliar no desenvolvimento saudável da criança:

"eu acho que o aleitamento materno é mui::to importante pra criança... é... no desenvolvimento da criança... é importante... eu acho que a criança tem que amamentar... mesmo aTÉ quando a mãe puder dar... muitas mães param de da: r r aos cinco meses... seis meses... eu acho que aquelas que... têm condições... que querem continuar... até um ano... por que não" $R 8$

Outro aspecto apontado como importante sobre o aleitamento materno na creche é a possibilidade de manutenção do contato da criança com a mãe. Isso facilita o processo de adaptação e permanência da criança na instituição, uma vez que as mães, quando estão aleitando, vêm mais vezes até a creche e a criança não estranha tanto sua ausência.

"o aleitamento é mui::to bom... tanto que deveria ser mai::s TEMPO... não SÓ se-is meses... porque dá dó (...) quando as mães não vinham... eles ficavam procurando na gente" $R 9$ 
Para alguns participantes, a manutenção do contato entre mãe e bebê, mediante o aleitamento, também é importante porque fortalece o vínculo entre eles.

"amamentar é MUITO bom:: e... também tem o lado a fase do contato... com a mã::e... estar com o bebê naquele momento... essa passagem de carinho de fazer a criança se sentir segura... aMAda pela mãe... porque amamentar é um ato de amor mesmo" $R 2$

$\mathrm{O}$ segundo tema, A prática do aleitamento materno na creche depende das mães, explica a visão de que a decisão de manter o aleitamento deve-se ao interesse e à disponibilidade materna, uma vez que a instituição não as impede de ir amamentar seus filhos.

"só cabe a mãe ter vontade mesmo... de fazer... e de vir amamentar seu filho" $R 2$

Tal percepção é construída a partir da constatação de que algumas mães já iniciam o desmame antes de matricular a criança na creche, pois ficam preocupadas com a manutenção dessa prática ao término da licença maternidade. Os funcionários entendem, então, que não há o que fazer no sentido de incentivar o aleitamento materno, visto que elas já chegam à creche decididas a interrompê-lo.

"ai vai depender dela \{mãe\}... porque a maioria das mães... já quando a criança retorna nos quatro meses... já não estão amamentando (...) ela já vem pra matrícula... ai já fala... eu vou fazer mais um mês de férias... vou ficar mais um mês em casa... aí a gente não fala nada... então tá.... já está comendo alguma coisa? não... mas assim que voltar eu já vou começar a dar o lei-te... porque eu não sei se eu não vou poder vir" $R 1$

Parece causar estranhamento às educadoras que, a despeito de conhecerem seu direito de amamentar, nem sempre as mães se valem dele para manter o aleitamento após a entrada da criança na creche.

"ai depende delas... do interesse da mãe... (...) que muitas sabem que têm o direi- to... mas aí às vezes... eu já não sei o motivo que elas NÃO vêm" $R 1$

No tema Facilidades Relacionadas ao Aleitamento Materno na Creche, no que se refere à instituição, os funcionários entendem que há um grande apoio para o aleitamento, uma vez que há total liberdade para a entrada das mães no serviço, ação favorável à manutenção dessa prática na creche. Essa liberdade pode ser reconhecida pela ausência de restrições, seja quanto ao momento da vinda da mãe, seja no tempo em que ela lá permanece. Todos os depoentes, em seus discursos, são enfáticos em garantir que a instituição não põe obstáculos à entrada da mãe rumo à sala de amamentação.

“a creche DÁ liberdade... dá apoio... elas ficam à vontade... não tem ninguém cobrando delas que já deu a hora... nem nada (...) também dá liberdade pra mãe dela vir no horário que ela quiser vir (...) a instituição dei::xa e é assim... a mãe pode vir" $R 1$

Os participantes lembram também que a legislação facilita a promoção do aleitamento materno, pois garante às mães o direito de se ausentarem do trabalho para amamentar, embora elas não saibam explicar o que está previsto na lei:

"não sei muito be::m não... mas todas \{mães\} que amamentam têm o direito... eu sei que é direito delas e a creche cede esse direito de elas virem amamentar" $R 3$

São relatadas, também, ações dos funcionários apontadas como facilitadoras do aleitamento materno na creche. Tais ações podem iniciar-se antes do ingresso da criança, com a investigação de sua alimentação habitual. Entretanto, observa-se que essa busca de informações visa primordialmente que as funcionárias possam organizar-se no cuidado da criança e até mesmo tende a focar-se em opções de alimentos que elas poderiam oferecer à criança no caso de as mães não conseguirem chegar a tempo. Veja-se um dos discursos a esse respeito: 
“ah... a gente pergun::ta... se ele vai continuar só mamando no peito... se pode oferecer outras... outra coisa... água... lei-te... essas coisas assim... e fala dos horários... tudo... assim" $R 4$

Quando a criança já está inserida na creche, ações de apoio e estímulo traduzem-se em garantir que as crianças não recebam outros alimentos em horários próximos da chegada das mães, bem como em dizer a elas que insistam no aleitamento, especialmente enquanto o bebê ainda não aceita bem outros alimentos.

"nó:::s que cuidamos dos beBÊS nós ajudamos... a gente pergunta pra elas \{mães\}... se elas vêm naquele horário então a gente não dá NADA... não oferece outro leite... a gente respeita... nós colaboRAmos bas::tante... pedimos para esperar... ainda falamos com elas $\{$ mães\}... olha fica mais um pouquinho... porque faz muito tempo que foi a última refeição... ele não aceitou bem... os que já estão comendo a sopinha... que tomam só aquele... ai a gente fala pra elas insistirem mais... no peito" R1

Também consideram uma forma de apoio falar para a mãe sobre a importância do aleitamento materno:

"a gente sempre fala... NOSsa... mãe... mas é tão importante.... estar amamentando... é bom pra saúde do seu filho... porque no leite materno... tem tudo o que a criança precisa... pro organismo da criança... então... o pouco que a gente pode ajudar a gente estimula... colocando a importância de amamentar" $R 2$

Até mesmo nas situações de maior dificuldade em atender à mãe, como durante o horário de almoço, quando há saída de uma funcionária da sala sobrecarregando aquela que permanece, as ADIs proporcionam a possibilidade de a mãe amamentar:

"mesmo que for nosso horário de almoço e estiver uma só na sala... a gente vai entregar a criança se ela vier na hora de almoço dela também... complementar" $R 3$

No que diz respeito às Dificuldades Re- lacionadas ao Aleitamento Materno na Creche, destaca-se a distância entre o serviço materno e a creche, e o tempo gasto no percurso: "ah... TÃO FÁcil não é... porque ela vai se deslocar do trabalho ... e às vezes um pouco correndo... então... às vezes ela tem até um tempinho assim determinado pra ela vir... mas tem que voltar logo... então... não é tão fácil" $R 2$

"a gente acha... VÊ que é diFÍcil pras MÃES amamentarem... devido ao hora::rio... o tempo de locomoção... eu falo aqui... do hospital para a creche... é:..... não é um caminho lon::GO... mas de até uns cinco dez mnul::tos" R3

Alguns respondentes disseram que o horário disponível para as mães amamentarem dificulta a prática de aleitar, uma vez que elas dependem da permissão da chefia para organizar os horários de saída.

"é o horário da mães... às vezes elas estão em um plantão com uma emergência... no caso de alguma enfermeira... elas não podem descer... não podem largar tudo e vi::r" R3

Ainda dentre as Dificuldades maternas em realizar o aleitamento materno na creche, aparece a consideração de que a sala disponível para o aleitamento não é adequada, pois o espaço é conjugado com a sala do berçário II.

"a única dificuldade que eu considero é em relação ao ambiente... SÓ... a sala aqui poderia ser outra" $R 6$

Duas participantes acrescentam que a instituição teria condições de proporcionar um local exclusivo para essa prática.

"nosso lugar não é um lugar MUI:.::TO apropriado... ma::s tem lugar:: SIM... espaço na creche que dá pra fazer isso be::m" $R 3$

Uma respondente do estudo expressou que as mães vêm amamentar agitadas, preocupadas com o trabalho, o que prejudica a prática do aleitamento na creche.

"elas \{mães\} vêm muito agiTAdas... elas vêm muito RÁ-PIDO lá de cima... e eu acho que também é isso... aí... eu não sei se elas vêm preocupadas... com alguma coisa... com 
o tempo pra voltar" $R 1$

Para a mesma funcionária, algumas mães ficam inseguras em manter o aleitamento materno na creche, pois se preocupam com risco de perda ou avaliações negativas no trabalho.

"porque a maioria das mães a gente percebeu que quando elas voltam... elas já não voltam pro mesmo lugar em que elas trabalhavam entendeu? às vezes elas são mudadas de setor:: são mudadas de horário... e elas já acham... e mesmo quando você volta de uma licença É:: tudo diferente... até você pegar no pique (...) assim essa insegurança de ter voltado agora... depois de muito tempo afastada... fica meio preocupada... com o serviço... de já chegar.. já ter que descer pra amamentar a criança... já deixar a outra colega cuidando da sua parte” R1

Ao lado das dificuldades maternas para manter o aleitamento na creche, também foram pontuados os problemas enfrentados pelas trabalhadoras. Estas se veem impossibilitadas de atender as crianças em aleitamento materno exclusivo, quando as mães não conseguem vir nos horários estipulados para as mamadas e não permitem a introdução de novos alimentos.

"aí... a gente fica meio perdido... na sala... porque a mãe não autoriza a gente a dar nada... nem... um chá... nem água... nem nada... nem... um leite assim... pra.... complementar.. enquanto ela não estiver aqui... então fica dificil... porque a gente faz de tudo pra criança ((tosse)) parar um pouco de chorar... a gente pega no colo... troca...

\section{DISCUSSÃO}

Apesar da grande quantidade de vantagens apresentadas sobre a amamentação, muitas mulheres decidem não amamentar seus filhos com leite materno. Essa decisão é motivada por questões culturais, pessoais e sociais desfavoráveis ao aleitamento materno, como as atitudes da família e de amigos próximos, além das dificuldades enfrentadas pela mulher para amamentar em locais públicos $\mathrm{e}$ no trabalho ${ }^{13}$.

Por esta razão, torna-se importante para os trabalhadores de saúde que atuam na promoção do aleitamento conhecer essas barreiras e colocar seus conhecimentos e habilidades em prol do apoio às mães, para que tomem suas decisões melhor amparadas.

No caso deste estudo, constata-se que há observância da lei, por parte do empregador das mães usuárias do serviço: as vagas para crianças menores de 1 ano são exclusivas para as funcionárias do hospital e elas podem deslocar-se até a creche durante o período laboral para amamentar suas crianças, de forma a possibilitar a manutenção do aleitamento. Isso é o que a maioria delas começa a fazer quando retorna ao trabalho. Entretanto, percebe-se que ter a creche não é suficiente, pois muitas mães desistem logo e algumas já chegam com a criança à instituição tendo desistido do aleitamento, talvez prevendo as dificuldades para acomodar todas suas atividades. Cabe, então, analisar se as práticas realizadas na creche podem ter alguma associação com essas situações.

Inicialmente, o fato dos participantes da investigação declararem considerar o aleitamento materno importante é um fator favorável a sua prática. Além de conhecimentos genéricos, como sua importância para a saúde, destaca-se que as ADIs identificam aspectos importantes do aleitamento, a partir da observação do cotidiano: ele facilita a adaptação e a permanência da criança na creche e fortalece o vínculo mãe-filho.

Por outro lado, percebe-se o escasso preparo dos trabalhadores do CI para assumir as orientações de apoio e incentivo ao aleitamento materno na creche, por exemplo, quando eles enfatizam que a prática depende das mães. Em suas falas, eles não se reconhecem como agentes que podem influenciar as decisões maternas e, portanto, influir na promoção do cresci- 
mento e desenvolvimento saudável da criança.

Eles afirmam a importância do aleitamento materno, bem como seu apoio e incentivo a essa prática na creche. Todavia denota-se certo despreparo para uma atuação profissional nesse sentido, ao não relatarem medidas específicas de apoio.

Evidenciou-se também que algumas mães não usam seu direito para amamentar, entretanto, não existem políticas reais entre a creche e o hospital que facilitem esse processo. Isso se confirma nas falas sobre as possíveis dificuldades enfrentadas pelas mães no local de trabalho, como o receio de serem mal vistas, ou nas dificuldades de acesso até a creche.

$\mathrm{O}$ aleitamento materno não deve ser visto como responsabilidade exclusiva da mulher. Muitas vezes, os sentimentos e as percepções da nutriz não são valorizados na determinação desse processo, induzindo-a a buscar justificativas que a livrem da responsabilidade de não conseguir amamentar ${ }^{5}$.

A formação de uma rede de apoio à amamentação poderia incrementar o acompanhamento pelo serviço de saúde, uma vez que a creche onde foi realizado esse estudo está vinculada a um hospital de ensino de grande porte e conta com médicos, enfermeiros, nutricionistas, psicólogos, fonoaudiólogos, dentistas e assistentes sociais. Esses profissionais poderiam se articular com a creche para promover e incentivar o aleitamento materno.

Todavia, alguns participantes são favoráveis à decisão das mães de interromperem o aleitamento materno antes de a criança entrar na creche, para evitar possíveis dificuldades no seu cotidiano de trabalho com a criança. Se houvesse um vínculo entre o hospital e a creche, os profissionais do CI conheceriam estratégias de incentivo e promoção ao aleitamento e estariam mais preparados para fazer esse apoio.

Os educadores infantis, assim como os profissionais de saúde, desempenham um papel relevante na assistência à mulher-mãe. Para tal, esses profissionais devem instrumentalizar- se com conhecimentos atualizados e habilidades, tanto no manejo clínico da amamentação como na técnica de aconselhamento.

Porém, observa-se que nem mesmo a recomendação de oferecer à criança o leite materno ordenhado na impossibilidade da mãe dirigir-se ao CI, é sugerida ou pensada como forma de apoio.

Dada a necessidade de promover, proteger e apoiar a prática do aleitamento materno e reduzir o desmame precoce e suas consequências sobre a saúde infantil, o Fundo das Nações Unidas para a Infância (UNICEF) e a Organização Mundial da Saúde (OMS), lançaram, em 1990, a iniciativa Hospital Amigo da Criança, que visa garantir a implementação dos 10 passos para o sucesso do aleitamento materno ${ }^{14}$. Um desses passos é não dar bicos artificiais ou chupetas a crianças amamentadas ao seio, o que implica oferecer o leite ordenhado com copinho. Este tem sido um procedimento avaliado em diversos estudos, possivelmente dado implicar uma grande mudança dos hábitos em voga tanto nos serviços quanto na comunidade, no que se refere ao uso da mamadeira.

Entretanto, estudos relacionados ao tema verificaram que, no caso de bebês recém-nascidos, a utilização do copo para oferecer alimentação quando eles não podem receber aleitamento materno não pode ser recomendada ${ }^{15}$. Seria necessário realizar estudos iniciando a utilização do copo com bebês maiores, como é o caso dos atendidos no CI, para constatar a melhor forma de oferecer o leite materno a eles e promover a manutenção desta prática.

Outro aspecto a ser verificado é a capacidade dos trabalhadores de saúde em contribuírem para essa adaptação do aleitamento da criança na creche. Um estudo de avaliação da implantação dos "10 passos..." nos hospitais brasileiros mostrou que o passo menos atendido nesses serviços foi "mostrar às mães como amamentar e como manter a lactação, mesmo se vierem a ser separadas de seus filhos" ${ }^{" 16}$. 
No que diz respeito às facilidades relacionadas ao aleitamento materno na creche identificadas no estudo, não são meros benefícios proporcionados pela creche, pelos profissionais e pela legislação. Os itens apresentados como facilidades são deveres e como tal precisam ser cumpridos.

Já quanto às dificuldades relacionadas ao aleitamento materno na creche, além de fatos concretos como a distância entre o trabalho e a creche, a percepção dos participantes do estudo acerca das preocupações maternas com suas ausências no trabalho para amamentar merece atenção. É curioso que as nutrizes sintam-se intimidadas em amamentar ou sintam-se em risco, uma vez que são funcionárias de um serviço de saúde que atende as pessoas em seu processo saúde-doença. É difícil compreender que o serviço não olhe para as necessidades da mulher.

Assim, nota-se a ausência de apoio social estruturado para assegurar a prática do aleitamento materno na creche, para que mãe/mulher possa se sentir mais segura.

Como já apresentado, o aleitamento materno é um dos cuidados essenciais à criança tendo em vista seu crescimento e desenvolvimento integrais. Atuar na promoção do crescimento e desenvolvimento infantil é responsabilidade das famílias e também da comunidade, trabalhadores da educação, saúde e serviço social, constituídos em sua rede de apoio.

Como elementos dessa rede, os trabalhadores têm um importante papel de engajar as famílias em processos de aprendizado e aquisição de habilidades para o cuidado, ajudá-las a compreenderem o processo e as necessidades de crescimento e desenvolvimento infantil, e pensarem em alternativas para o atendimento da criança ${ }^{17}$.

Para tanto, pode-se estimular a parceria entre as áreas da saúde e da educação no contexto da atenção à criança em instituições de educação ${ }^{18}$. Para as autoras, "a importância dessa integração consiste na necessidade de aprimorar o olhar para o cuidado infantil, compreendendo-o como alicerce para a promoção da saúde e do desenvolvimento da criança, em todos os espaços onde ela é atendida".

Foram analisados conhecimentos e práticas de trabalhadores de uma creche sobre o aleitamento materno, tendo como contraponto a bibliografia sobre o tema, bem como os relatos sobre a efetividade do aleitamento nessa instituição.

A manifestação de conhecimentos empíricos por parte dos trabalhadores e que podem ser decisivos na manutenção ou não do aleitamento materno aponta para a necessidade de parceria entre as áreas da saúde e da educação, a fim de preparar os trabalhadores do CI não somente sobre os benefícios do aleitamento materno, mas também de estratégias de ação para que se tornem agentes promotores dessa prática.

Corrobora-se a idéia de que a mãe/mulher deve ser o foco do aleitamento materno, decidindo se vai investir ou não nessa prática, entretanto, acredita-se que a creche poderia intervir facilitando o processo. Com isso, a decisão materna poderia ser mais bem informada e efetivamente apoiada.

O CI como equipamento social poderia interagir com o hospital e com as mães, constituindo uma rede de apoio, para pensarem juntos sobre as reais dificuldades para a prática do aleitamento materno nesse local e possibilidades de superação, face o desejo da mãe em seguir amamentando.

Compartilhar a responsabilidade entre o hospital, a instituição de educação infantil e a mãe/mulher, demanda uma estrutura de amparo para as mães, na qual elas possam ser ouvidas, expondo suas dúvidas, troquem experiências e elaborem conjuntamente com o Centro Infantil e o hospital estratégias para lidar com as dificuldades. 


\section{REFERÊNCIAS}

1. Organização Mundial da Saúde (OMS), Fundo das Nações Unidas para Infância e Adolescência (UNICEF). Amamentação garante saúde ao bebê e à mãe. Brasília; 1989 [acesso em 15 mar 2007]. Disponível em: http://www.unicef.org/brazil/ aleitamento.htm

2. Brasil. Ministério da Saúde. Instituto Nacional de Alimentação e Nutrição (INAN). Proteção, promoção e apoio ao aleitamento materno: o papel especial dos serviços maternos-infantis. Uma declaração conjunta OMS/UNICEF. Brasília: 1989.

3. Braga NP, Rezende MA, Fujimori E. Amamentação em creches no Brasil. Rev. Bras. Crescimento Desenvolv Hum. 2009; 19(3): 465-474.

4. Narchi NZ, Fernandes RAQ, Dias LA, Novais DH. Variáveis que influenciam a manutenção do aleitamento materno exclusivo. Rev. Esc. Enferm. USP. 2009; 43(1): 87-94.

5. Ichisato SMT, Shimo AKK. Revisitando o desmame precoce através de recortes da história. Rev. Latino-Am Enfermagem. 2002; 10(4):578-85.

6. Almeida JAG, Novak FR. Amamentação: um híbrido natureza-cultura. J. Pediatr. 2004; 80(5):119-125.

7. Sousa FRN, Taveira GS, Alemida RVD, Padilha WWN. OAleitamento Materno e sua Relação com Hábitos Deletérios e Maloclusão Dentária. Pesq. Bras. Odontoped. Clin. Integr. 2004; 4(3): 211-216.

8. Spinelli MGN, Sesoko EH, Souza JMP, Souza SB de. A situação de aleitamento materno de crianças atendidas em creches da Secretaria da Assistência Social do Município de São Paulo - Região Freguesia do Ó. Rev. Bras. Saúde Matern. Infant. 2002; 2 (1): 23-28.

9. Veríssimo MLOR, Rezende MA, Fonseca RMGS . Relações creche família segundo educadoras de creches. Rev Bras. Crescimento Desenvolv. Hum. 2003; 13(1): 54-68.

10. Ministério da Educação (BR), Secretaria da Educação. Lei de Diretrizes e Bases para a Educação Nacional. Lei no 9394 de 20 de dezembro de 1996. Brasília: MEC; 1996 [acesso em 15 mar 2007]. Disponí- vel em: http://planetaeducacao.com.br/ novo/legislação/ldb.pdf

11. Bressani, MC; Bossa CA; Lopes RS. Aresponsividade educadora-bebê em um berçário: um estudo exploratório. Rev. Bras. Crescimento. Desenvolv. Hum. 2007;17(3): 21-36.

12. Koch IG. A inter-ação pela linguagem. $10^{\mathrm{a}}$ ed. São Paulo: Contexto; 2006. p.82-107.

13. Renfrew MJ, Woolridge MW, Ross McGill H. Enabling women to breastfeed. Interventions which support or inhibit breastfeeding. A structured review of the evidence. London: The Stationery Office, 2000, p. 1-4.

14. Unicef. Dez Passos para o Sucesso do Aleitamento Materno; 1991 [acesso em 20 julho 2008]. Disponível em: http:// www.unicef.org/brazil

15. Flint A, New K, Davies MW. Alimentación con taza versus otras formas de alimentación enteral complementaria para los neonatos que no pueden alimentarse solamente con leche materna (Revisión Cochrane traducida). En: La Biblioteca Cochrane Plus, 2008 Número 2. Oxford: Update Software Ltd. 2006 [acesso em 05 mar 2009] Disponible en: http:// www.update-software.com.

16. Araújo MFF, Otto AFN, Schimtz BAS. Primeira avaliação do cumprimento dos "Dez Passos para o Sucesso do Aleitamento Materno" nos Hospitais Amigos da Criança do Brasil. Rev. Bras. Saúde Matern. Infant. 2003; 3(4). p. 411-19.

17. Veríssimo MLOR. O desenvolvimento infantil e o cuidado da criança pela família. In: SMS; PSF. (Org.). NOSSAS CRIANÇAS: janelas de oportunidades. São Paulo: Secretaria Municipal da Saúde e Programa da Saúde da Família. 2002 [acesso em 05 mar 2009] Disponível em http:// www.ee.usp.br/pesquisa/grupromo

18. Veríssimo MLOR, Alves RCP. Os educadores de creche e o conflito entre cuidar e educar. Rev. Bras. Crescimento. Desenvolv. Hum. 2007; 17(1): 13-25.

Recebido em 02/02/09 Modificado em 06/07/10 Aceito em 12/08/10 